\title{
The Extraction Technology of Flavonoids from Buckwheat
}

\author{
Wang $L^{1 *}$ and Bai $X^{2}$ \\ ${ }^{1}$ The College of Life Science, Yangtze University, Jingzhou, Hubei, China \\ ${ }^{2}$ The First People's Hospital of Jingzhou, Jingzhou, Hubei, China
}

\begin{abstract}
Buckwheat (Fagopyrum esculentum) is a kind of medicinal and edible crops with high Flavonoid content. Flavonoids from tartary buckwheat have significant therapeutic effects on vascular diseases, diabetes and obesity. In this paper, the extracting technologies of flavonoids from buckwheat were investigated. The results showed that the optimum parameters for the extraction is temperature $60^{\circ} \mathrm{C}$, alcohol concentration $60 \%$, solid to liquid ratio $1: 20$, $\mathrm{pH}=2$, duration $120 \mathrm{~min}$.
\end{abstract}

Keywords: Buckwheat; Flavonoid; Extraction; Orthogonal design

\section{Introduction}

Flavonoids have anti-inflammatory, antiallergic, diuretic, antispasmodic, antitussive and hypolipidemic effects, and have significant therapeutic effects on vascular diseases, diabetes and obesity $[1,2]$. Buckwheat (Fagopyrum esculentum) is a kind of medicinal and edible crops. The content of flavonoids in Tartary buckwheat is particularly rich, and the effect is the most remarkable $[3,4]$. We analyzed the effects of the extraction conditions to tartary buckwheat flavonoids and got the optimal preparing conditions for Tartary buckwheat flavonoids. The results of this work will lay the foundation of theory and application for the further study of Tartary buckwheat flavonoids.

\section{Materials and Methods}

\section{Preparation of buckwheat flour}

Tartary buckwheat (Chuanqiao No. 1) was purchased from Liangshan Yi Autonomous Prefecture. Buckwheat was grinded into flour using flour mill, then filtered using 200 mesh sieve.

\section{Determination of flavonoid content}

Accurately prepare $0.1 \mathrm{mg} / \mathrm{mL}$ rutin methanol solution (rutin standard solution). Add $0.1 \mathrm{~mL}, 0.2 \mathrm{~mL}, 0.4 \mathrm{~mL}, 1.0 \mathrm{~mL}, 0.6 \mathrm{~mL}$, $0.8 \mathrm{~mL}$ of rutin standard liquid in the calibration tubes and add the $100 \%$ methanol solution volume up to $1.0 \mathrm{~mL}$, and then add the $2 \mathrm{~mL}$ $0.1 \mathrm{~mol} / \mathrm{L}$ and $3 \mathrm{~mL} 1 \mathrm{~mol} / \mathrm{L}$ acetic acid potassium chloride. Finally, add $30 \%$ ethanol up to $10 \mathrm{~mL}$, after resting $30 \mathrm{~min}$, the absorbance was measured at $420 \mathrm{~nm}$. The standard curve was made with rutin concentration $\mathrm{X}$ as abscissa and absorbance difference $(\mathrm{Y})$ as ordinate. The regression equation was $y=8.0068 \mathrm{x}$, and the correlation coefficient was $\mathrm{r}=0.9996$ (Figure 1) [5,6].

The optimization of the preparation process of buckwheat flavonoids

To optimize the preparation process of buckwheat flavonoids, the major factors and their levels were determined according the effects of various factors (such as solid to liquid ratio (S/L), ethanol concentration, extraction temperature, extraction time, $\mathrm{pH}$ value) on buckwheat flavonoid content. The optimum preparation conditions of buckwheat flavonoids were further determined using orthogonal test.

\section{Results and Discussion}

\section{The effects of solid to liquid ratio on buckwheat flavonoid}

The buckwheat flavonoids were extracted at different solid to liquid ratio for $60 \mathrm{~min}$ with ethanol concentration is $50 \%$ and temperature is $30^{\circ} \mathrm{C}$. The buckwheat flavonoids content was analyzed. The optimum solid to liquid ratio is 1:20 (Figure 2).

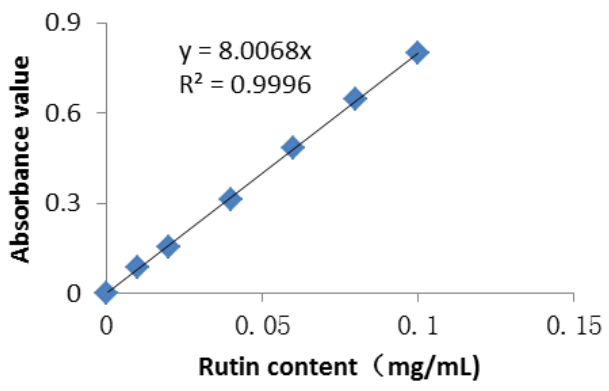

Figure 1: Standard curve of rutin.

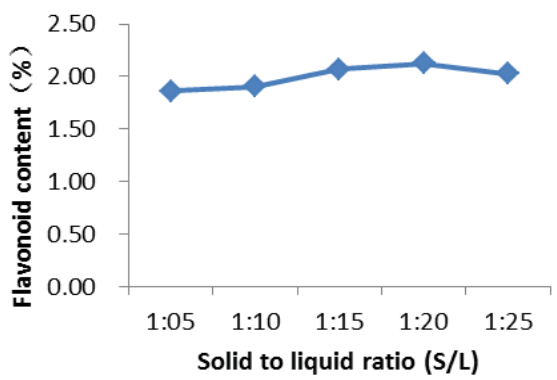

Figure 2: Effects of solid to liquid ratio on flavonoid extraction.

*Corresponding author: Wang L, The College of Life Science, Yangtze University Jingzhou, Hubei, China, Tel: +8607168066257; E-mail: ljwang516@126.com

Received July 26, 2017; Accepted August 10, 2017; Published August 17, 2017

Citation: Wang L, Bai X (2017) The Extraction Technology of Flavonoids from Buckwheat. Agrotechnology 6: 164. doi: 10.4172/2168-9881.1000164

Copyright: @ 2017 Wang L, et al. This is an open-access article distributed under the terms of the Creative Commons Attribution License, which permits unrestricted use, distribution, and reproduction in any medium, provided the original author and source are credited. 


\section{Effects of ethanol concentration on buckwheat flavonoid extraction}

The buckwheat flavonoids were extracted at different ethanol concentration for $60 \mathrm{~min}$ with solid to liquid ratio is $1: 10$ and temperature is $25^{\circ} \mathrm{C}$. The buckwheat flavonoids content was analyzed. The optimum ethanol concentration is $60 \%$ (Figure 3 ).

\section{Effects of extracting time on buckwheat flavonoid extraction}

The buckwheat flavonoids were extracted at different extracting time with solid to liquid ratio is $1: 20, \mathrm{pH} 5$, ethanol concentration is $50 \%$ and temperature is $50^{\circ} \mathrm{C}$. The buckwheat flavonoids content was analyzed. The optimum extracting time is $160 \mathrm{~min}$ (Figure 4).

\section{Effects of temperature on buckwheat flavonoid extraction}

The buckwheat flavonoids were extracted at different temperature with solid to liquid ratio is $1: 20, \mathrm{pH} 5$, ethanol concentration is $50 \%$ and extracting time is $60 \mathrm{~min}$. The buckwheat flavonoids content was analyzed. The optimum extracting temperature is $70^{\circ} \mathrm{C}$ (Figure 5).

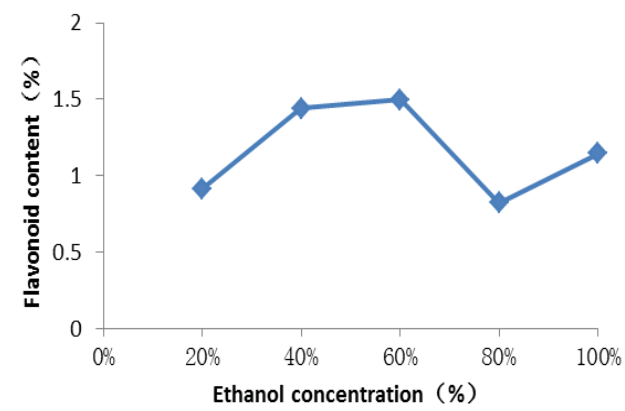

Figure 3: Effects of ethanol concentration on flavonoid extraction.

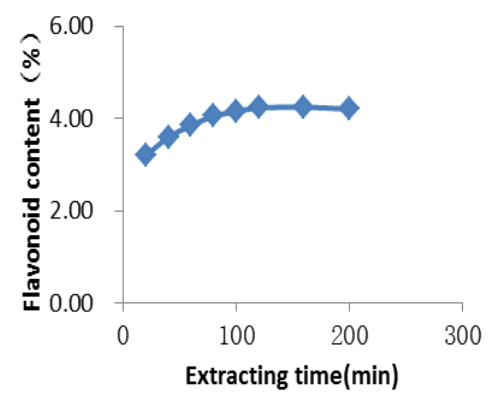

Figure 4: Effects of extracting time on flavonoid extraction.

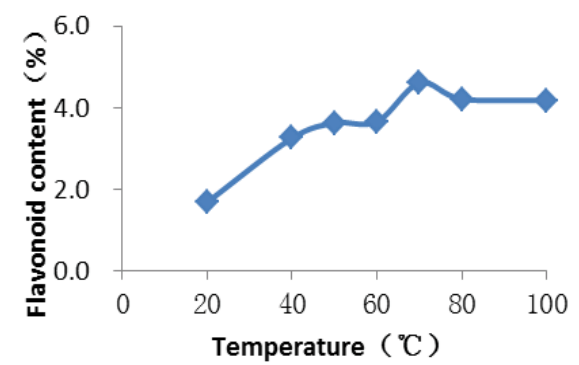

Figure 5: Effects of temperature on flavonoid extraction.

\section{Effects of $\mathrm{pH}$ values on buckwheat flavonoid extraction}

The buckwheat flavonoids were extracted at different $\mathrm{pH}$ values with solid to liquid ratio is $1: 20$, ethanol concentration is $50 \%$, temperature is $50^{\circ} \mathrm{C}$ and extracting time is $60 \mathrm{~min}$. The buckwheat flavonoids content was analyzed. The optimum pH is 2 (Figure 6).

\section{Orthogonal experiment of buckwheat flavonoid extraction}

According the effects of individual factors on buckwheat flavonoid extraction, orthogonal experiments were conducted using extracting time, temperature, solid-to-liquid ratio $(\mathrm{S} / \mathrm{L})$ and $\mathrm{pH}$ as factors and flavonoid content as index (Tables 1 and 2).

As the results shown in the Table 2, solid-to-liquid ratio had the largest effect on flavonoid content. The $\mathrm{pH}$ Value had the second largest effect on flavonoid content. Temperature had the third largest effect on flavonoid content. Exacting time had the fourth largest effect on flavonoid content. The optimum parameters for producing technology of flavonoids from buckwheat using ethanol solvent are A1B2C2D1, that is exacting time $120 \mathrm{~min}$, temperature at $60^{\circ} \mathrm{C}$, solidliquid ratio 1:20, $\mathrm{pH}$ 2. The sequence of effects on flavonoid content: $\mathrm{C}>\mathrm{D}>\mathrm{B}>\mathrm{A}$.

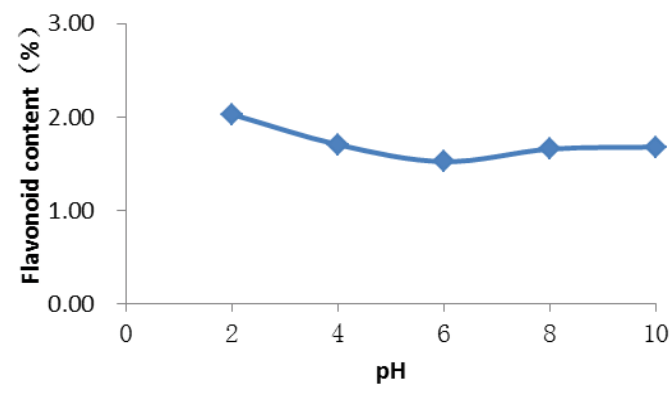

Figure 6: Effects of $\mathrm{pH}$ on flavonoid extraction.

\begin{tabular}{|c|c|c|c|c|}
\hline Level & $\begin{array}{c}\text { A } \\
\text { (Extracting } \\
\text { time/min) }\end{array}$ & $\begin{array}{c}\mathbf{B} \\
\left.\text { (Temperature/ }{ }^{\circ} \mathbf{C}\right)\end{array}$ & $\begin{array}{c}\mathbf{C} \\
\text { (Solid-liquid } \\
\text { ratio) }\end{array}$ & $\mathbf{D}$ (pH) \\
\hline 1 & 120 & 50 & $01: 15$ & 2 \\
\hline 2 & 160 & 60 & $01: 20$ & 6 \\
\hline 3 & 180 & 70 & $01: 25$ & 10 \\
\hline
\end{tabular}

Table 1: Factor level table.

\begin{tabular}{|c|c|c|c|c|c|}
\hline S. No. & $\begin{array}{c}\text { A } \\
\text { (Extracting } \\
\text { time/min) }\end{array}$ & $\begin{array}{c}\mathbf{B} \\
\left(\text { Temperature/ }{ }^{\circ} \mathrm{C}\right)\end{array}$ & $\begin{array}{c}\mathbf{C} \\
\text { (Solid-liquid } \\
\text { ratio) }\end{array}$ & $\mathbf{D}$ (pH) & $\begin{array}{c}\text { Flavonoid } \\
\text { Content } \\
\mathbf{( \% )}\end{array}$ \\
\hline 1 & $1(120 \mathrm{~min})$ & $1\left(50^{\circ} \mathrm{C}\right)$ & $1(1: 15)$ & $1(2)$ & 3.895 \\
\hline 2 & $1(120 \mathrm{~min})$ & $2\left(60^{\circ} \mathrm{C}\right)$ & $2(1: 20)$ & $2(6)$ & 4.017 \\
\hline 3 & $1(120 \mathrm{~min})$ & $3\left(70^{\circ} \mathrm{C}\right)$ & $3(1: 25)$ & $3(10)$ & 2.26 \\
\hline 4 & $2(160 \mathrm{~min})$ & $1\left(50^{\circ} \mathrm{C}\right)$ & $2(1: 20)$ & $3(10)$ & 3.59 \\
\hline 5 & $2(160 \mathrm{~min})$ & $2\left(60^{\circ} \mathrm{C}\right)$ & $3(1: 25)$ & $1(2)$ & 2.576 \\
\hline 6 & $2(160 \mathrm{~min})$ & $3\left(70^{\circ} \mathrm{C}\right)$ & $1(1: 15)$ & $2(6)$ & 3.973 \\
\hline 7 & $3(180 \mathrm{~min})$ & $1\left(50^{\circ} \mathrm{C}\right)$ & $3(1: 25)$ & $2(6)$ & 2.027 \\
\hline 8 & $3(180 \mathrm{~min})$ & $2\left(60^{\circ} \mathrm{C}\right)$ & $1(1: 15)$ & $3(10)$ & 3.872 \\
\hline 9 & $3(180 \mathrm{~min})$ & $3\left(70^{\circ} \mathrm{C}\right)$ & $2(1: 20)$ & $1(2)$ & 4.214 \\
\hline $\mathrm{K} 1$ & 10.172 & 9.512 & 11.74 & 10.685 & - \\
\hline $\mathrm{K} 2$ & 10.139 & 10.465 & 11.821 & 10.017 & - \\
\hline $\mathrm{K} 3$ & 10.113 & 10.447 & 6.863 & 9.722 & - \\
\hline $\mathrm{R}$ & 0.02 & 0.317667 & 1.652667 & 0.321 & - \\
\hline
\end{tabular}

Table 2: $L_{9}\left(3^{4}\right)$ flavonoid extracting orthogonal experiment design and results. 


\section{Conclusion}

The main factors affecting the extraction of flavonoids were solidliquid ratio, $\mathrm{pH}$ value, and extraction temperature and extraction time. Through the analysis of single factor gradient experiment and orthogonal experiment, the optimum extraction conditions were obtained: the extraction temperature was $60^{\circ} \mathrm{C}$, the concentration of ethanol was $60 \%$, the ratio of material to liquid was $1: 20$, and $\mathrm{pH}$ was 2 .

\section{References}

1. Li D, Li X, Ding X (2010) Composition and antioxidative properties of the flavonoid-rich fractions from tartary buckwheat grains. Food Sci Biotechnol 19: 711-716.
2. Sun T, Ho CT (2005) Antioxidant activities of buckwheat extracts. Food Chem 90: $743-749$.

3. Yao H, Li C, Zhao H, Zhao J, Chen H, et al. (2017) Deep sequencing of the transcriptome reveals distinct flavonoid metabolism features of black tartary buckwheat (Fagopyrum tataricum Garetn.). Prog Biophys Mol Bio 124: 49-60.

4. Li B, Li Y, Hu Q (2016) Antioxidant activity of flavonoids from tartary buckwheat bran. Toxicol Environ Chem 98: 429-438.

5. Liu B, Zhu Y (2007) Extraction of flavonoids from flavonoid-rich parts in tartary buckwheat and identification of the main flavonoids. J Food Eng 78: 584-587.

6. Sathishkumar $T$, Baskar $R$, Shanmugam $S$, Rajasekaran $P$, Sadasivam $S$, et al. (2008) Optimization of flavonoids extraction from the leaves of Tabernaemontana heyneana wall. using L16 orthogonal design. Nature Sci 6: 10-21. 